\title{
Lessons From a Japan-Korea Collaboration on Medical Response Training for a Nuclear or Radiological Emergency, Assuming Mass Casualty
}

Takakiyo Tsujiguchi, MS; Maiko Kitajima, PhD; Toshiko Tomisawa, PhD; Yuki Shiroto, MS; Ryohei Yamada, MS; Kyoji Saito, MD; Hiroyuki Hanada, MD, PhD; Young Woo Jin, MD, PhD; Minsu Cho, MD, PhD; Seongjae Jang, PhD; Hyunjung Kim, PhD; Minjung Pak, PhD; Toshiya Nakamura, PhD

\section{$\mathrm{T}$} he "2017 Radiation Emergency Medicine, Education and Training Course" (REM 2017) was held in Ulsan, South Korea, from June 21 to 22, 2017. This training session is organized by the Korea Institute of Radiological and Medical Sciences (KIRAMS), which conducts practical training in medical treatments during nuclear disasters based on the international standards for radiation protection. The practical training began with the assumption that a large-scale earthquake had caused an on-site emergency at the Kori Nuclear Power Plant (NPP); the aim of this training was to enhance control of the command system, information sharing, confirmation of triage, and patient distribution during an emergency situation. In this training, our group (the Japanese team) participated in REM as a radiation emergency medical assistance team including doctors, nurses, radiologic technologists, and logistics personnel, and cooperated with Korea's radiation emergency medical assistance team. In this study, we briefly introduce the contents of REM 2017 and discuss how we can make use of it in future education on nuclear disaster response.

Table 1 presents the REM 2017 schedule. More than 100 participants from various participating organizations, including primary and secondary radiation emergency hospitals in South Korea, ${ }^{1}$ and a large number of institutions participated in this training program. On the first day, we learned about the triage method ${ }^{2}$ and training scenario, and the second day involved field training.

During the field training, we participated in the operation of the nuclear disaster countermeasure headquarters. We were introduced to the activities performed by the headquarters, and its main control was undertaken by KIRAMS' Radiation Emergency Medical Assistance Team (REMAT). After the nuclear disaster countermeasure headquarters' tent was set up, the following preparations were completed: installation of laptops with wireless Internet connection, distribution

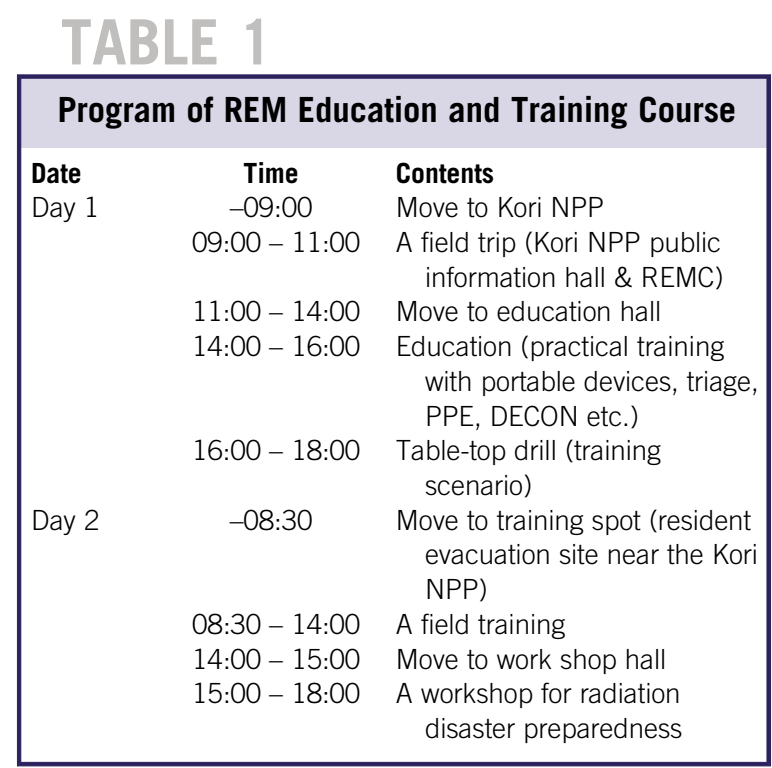

Abbreviations: NPP, nuclear power plant; REMC, Radiation Emergency Medical Center; PPE, personal protective equipment; DECON, decontamination of radioactive materials.

of transceivers to each team, and installation of whiteboards for chronology. KIRAMS has launched a mobile application information system called Korea-Radiation Emergency Medicine (K-REM) in South Korea to enable real-time, accurate information exchange between the headquarters (command post) and responders (REMAT) dispatched to the accident scene. As the residents and nuclear power staff arrived at the triage area, triage began in each tent. During the triage, each person's information was reported to the headquarters, written on the white board, and simultaneously recorded in the K-REM application. Particularly, information on patients who needed to be transported from a vast area was immediately shared with the headquarters, and as soon as the control team decided the patients' destination, instructions were sent to the triage tent.

In disaster medicine, including during nuclear accidents, collection and management of information is 
very important. We not only learned about decontamination and how to wear personal protective equipment but also became keenly aware of the importance of disaster headquarters management in education. In fact, we are currently developing an active learning program to enable responders to learn about information management as well as the operation of a nuclear emergency countermeasure headquarters. ${ }^{3}$ We believe that the stakeholders in charge of responder education can improve the effectiveness of education by referring to this information.

\section{About the Authors}

Hirosaki University Graduate School of Health Sciences, Department of Radiation Science; 66-1 Hon-cho, Hirosaki 036-8564, Japan (Mr Tsujiguchi, Mr Shiroto, Mr Yamada); Hirosaki University Center for Radiation Support and Safety; 66-1 Hon-cho, Hirosaki 036-8564, Japan (Mr Tsujiguchi); Hirosaki University Graduate School of Health Sciences, Department of Nursing Science; 66-1 Hon-cho, Hirosaki 036-8564, Japan (Drs Kitajima, Tomisawa); Aomori Prefectural Central Hospital; 2-1-1 Higashi-Tsukurimichi, Aomori 030-8553, Japan (Drs Saito, Hanada); Korea Institute of Radiological $\mathcal{E}$ Medical Sciences; 75 Nowon-ro, Nowon-gu, Seoul, Korea (Drs Jin, Cho, Jang, Kim, Pak) and Hirosaki University Graduate School of Health Sciences, Department of
Bioscience and Laboratory Medicine; 66-1 Hon-cho, Hirosaki 036-8564, Japan (Dr Nakamura).

Correspondence and reprint requests to Toshiya Nakamura, Hirosaki University Graduate School of Health Sciences, Department of Bioscience and Laboratory Medicine; 66-1 Hon-cho, Hirosaki 036-8564, Japan (e-mail: toshiyan@ hirosaki-u.ac.jp).

\section{Funding}

This study was financially supported by "Nuclear Regulatory Human Resources Development Project, Nuclear Regulation Authority, Japan" and "Strategic Theme 3: "International Education and Research Project based for Safety $\&$ Security on Radiation Medicine", Hirosaki University.

\section{REFERENCES}

1. Cho MS, Seong KM, Park CY, et al. Sustainable medical preparedness and response system for radiation emergencies in republic of Korea. Radiat Prot Dosimetry. 2018;182:20-24.

2. Saga R, Hosokawa Y, Saito Y, et al. Report on radiation emergency medicine education and training course. Radiat Envion Med. 2016;5(2):50-55.

3. Tsujiguchi T, Ito K, Sato D, et al. The development of an active learning program for the medical responders in a nuclear disaster. Disaster Med Public Health Prep. 2019;May 27:1-6. 